\title{
Har sikring av Tromsøbrua hindret selvmord?
}

\author{
Av Marianne Larssen og Gro Berntsen
}

\section{SAMMENDRAG}

Bruhopp som selvmordsmetode er et forholdsvis sjeldent fenomen, men en svært dødelig metode. Etter en forholdsvis kort periode på under ett år med flere selvmord fra Tromsøbrua, ble det besluttet at brua skulle sikres. Et forhøyet rekkverk på ble montert på brua. RVTS Nord fikk oppdraget, i samarbeid med politiet i Tromsø, å samle registreringer om aktivitet på brua og evaluere tiltaket. Siden det er to bruer nært knyttet til Tromsø var det interessant å følge med på utviklingen på Sandnessundbrua for å se om selvmordsaktiviteten flyttet seg til denne brua. Evalueringen av sikringstiltaket er basert på politiets registreringer om meldinger og utrykninger til bruene i Troms $\varnothing$, fra 01.01.04 til 31.12.14, to år før og ni år etter sikring. Registeringene omfatter all aktivitet med tilknytning til Tromsøbrua og Sandnessundbrua, som noen har opplevd så bekymringsfull at de har kontaktet politiet. Artikkelen besvarer spørsmålet: «Har sikring av Tromsøbrua hindra selvmord?» Selvmord ved utsprang fra høyt sted er en lite brukt selvmordsmetode, derfor blir det små tall når vi kun ser på de som har hoppet. Evalueringen av sikringa av Troms $\varnothing$ brua gir likevel noen indikasjoner på virkningen av sikringstiltaket og dermed mer kunnskap om brusikring som selvmordsforebyggende tiltak i Troms $\varnothing$. En av bekymringene i forkant av sikringa, var den unge alderen til personene som døde av hopp fra brua. De fleste var under 20 år. Vi finner ikke den samme aldersgruppa blant de som har hoppet fra Sandnessundbrua etter sikring av Tromsøbrua. Våre data viser at det ikke har vært en økning av dødsfall ved hopp fra Sandnessundbrua etter sikring av Tromsøbrua. På Tromsøbrua har det ikke vært hopp med døden til følge etter sikring. Til tross for små tall som betyr at vi må være forsiktig med å trekke bastante konklusjoner, kan vi si at sikringen har hatt en forebyggende effekt. Både generelt og i forhold til den unge aldersgruppen som døde ved hopp fra Tromsøbrua før sikring.
Bridge jump as a suicide method is a relatively rare phenomenon, but a very deadly method. After a relatively short period, for less than one year, with several suicides from the Troms $\varnothing$ Bridge, it was decided that the bridge should be secured with an elevated railing RVTS Nord, in cooperation with the police in Troms $\varnothing$, has collected records of activity on the bridge and has evaluated the measure.

Since there are two bridges close to Troms $\varnothing$, it was also interesting to follow developments on the Sandnessund Bridge to see if the suicide activity moved to this bridge. The evaluation of the security measure is based on police records of messages and calls to the bridges in Tromsø, from 01.01.04 to 31.12.14, two years before and nine years after the security measure was implemented. The registrations include all activity related to the Tromsø and Sandnessund bridges, where someone has experienced the situation severe enough to contact the police. The article answers the question: "Has the safety barriers on the Tromsø Bridge prevented suicide?" Suicide due to jumping is a rare suicide method; therefore, we operate with small numbers when we only look at those who have jumped. However, the evaluation of the safety barriers on the Tromsø Bridge provide some indication of the effect of the safety measures and thus more knowledge on what restriction to suicide means as a suicide preventive measure in Tromsø. One of the concerns ahead of the safety barriers was the young age of the people who died by jumping off the bridge. Most of them were under 20 years old. We cannot find the same age group among those who jumped from the Sandnessund Bridge after securing the Tromsø Bridge. Our data shows that there has not been an increase in deaths from the Sandnessund Bridge after the securing of the Tromsø Bridge. There has been no deaths by jumping off the Tromsø Bridge after securing it. In spite of small numbers, which means we have to be careful in drawing conclusions, we may say that the security railing has had a preventive effect. Both generally and specifically on the young people dying by jumping off the bridge before securing it. 


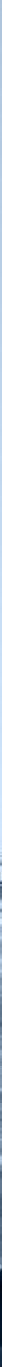

Det forhøyede gjerdet på Tromsøbrua. Foto: Ann Karin Furskognes.

DEN 9. DESEMBER 2005 ble det montert et forhøyet rekkverk på Tromsøbrua, for å hindre mennesker i å ta livet sitt ved å hoppe fra brua. Bruhopp som selvmordsmetode er et forholdsvis sjeldent fenomen, men en svært dødelig metode (Elnour \& Harrison, 2008). En norsk studie viser at omtrent én prosent av alle registrerte selvmord i Norge i perioden 1999-2010 ble utført ved hopp fra en bru (Sæheim et.al, 2016). Flere studier har funnet at det er særlig høye og spektakulære bruer, ofte i nærheten av byer og psykiatriske sykehus, som har en tendens til å bli valgt som sted for utsprang (ibid.).

Tromsø by ligger på Tromsøya. Đya er knyttet til fastlandet med Tromsøbrua, og til Kvaløya med Sandnessundbrua. På Tromsøya ligger et psykiatrisk sykehus, med omtrent like lang avstand til begge bruene. Det som først og fremst skiller de to bruene er deres nærhet til sentrum av byen. Tromsøbrua er mer eller mindre en del av sentrum og lett tilgiengelig. Fra sentrum til Sandnessundbrua er avstanden cirka 6,5 km.

Etter en forholdsvis kort periode på under ett år med flere selvmord fra Tromsøbrua, ble det besluttet at brua skulle sikres. Involverte fagpersoner forstod noen av disse selvmordene som «impulshopp» der unge mennesker hoppet i affekt. Tromsøbrua oppfyller flere av forutsetningene for å bli et såkalt «hot-spot» for selvmord (Larsen \& Karlsen, 2016). Dette ble brukt som et argument for at brua burde sikres.

Å redusere tilgang til metode er et selvmordsforebyggende tiltak (Mann et al. 2005). Spesielt gielder dette hvis metoden er allment tilgiengelig og ikke lett kan erstattes av andre lignende metoder (Sarchiapone et.al, 2011). Et forhøyet rekkverk på brua giør det vanskeligere å hoppe og dermed får personene som vil hoppe tid til ny overveielse. I tillegg gir det forbipasserende mulighet til å komme i kontakt med personen og om mulig forhindre at han eller hun hopper.

Etter sikringen av Tromsøbrua fikk RVTS Nord i oppdrag å evaluere tiltaket. Oppdraget fikk vi fra daværende kommunelege i Tromsø. Siden det er to bruer knyttet til Tromsøya var det interessant å følge med på utviklingen på Sandnessundbrua etter sikringen av Tromsøbrua, for å se om selvmordsaktiviteten flyttet seg til denne brua. Registreringene har resultert i tre evalueringsrapporter (se rvtsnord.no for tilgang til disse).

\section{Metode}

Evalueringen ble giort i samarbeid med politiet. I en tiårsperiode har vi, med utgangspunkt i politiets data, samlet og registrert det som har blitt oppfattet som bekymringsfull aktivitet på Tromsø- og Sandnessundbrua. 
Behovet for eventuelle godkjenninger for å samle dataene ble diskutert med daværende forskningsleder ved psykiatrisk forskningsavdeling, UNN. Konklusjonen var at det ikke var nødvendig med godkjenning fra REK for å registrere dataene fra politiet da opplysningene var anonymisert. Denne avgiørelsen har i ettertid vært diskutert med REK Nord. De konkluderer med at dataene ikke kan anses som helseopplysninger og derfor ikke et anliggende for godkjenning i REK. Prosjektet innhentet tillatelse fra politiet til innsyn i og bruk av deres data om bekymringsfull aktivitet på de to aktuelle bruene.

Mellom 01.01.2004 og 31.12.2014 har vi fått tilsendt politiets registreringer om meldinger og utrykninger til bruene i Tromsø. Registeringene omfatter all aktivitet med tilknytning til Tromsøbrua og Sandnessundbrua som noen har opplevd så bekymringsfull at de har kontaktet politiet. Informasionen fra politiet inneholdt dato, klokkeslett, bru, hopp/ikke hopp, død/ikke død, kjønn, fødselsår samt tiltak umiddelbart igangsatt av politiet.

Intensjonen med sikringen av Tromsøbrua var å forhindre hopp med døden til følge, og politiets registreringer alene gir begrenset informasjon om bekymringsfull aktivitet og personene som utfører den. Med bakgrunn i dette har vi i denne artikkelen kun valgt å undersøke registreringene som handler om giennomførte hopp.

I tillegg til registreringen har vi hatt flere møter med politiet i Tromsø. Diskusjoner fra disse møtene er med når vi skal tolke og prøve å forstå aktiviteten på de to bruene i Tromsø.

\section{Datagrunnlag}

I perioden 01.01.2004 til 31.12.2014 har politiet registrert til sammen 455 hendelser på Sandnessundbrua og Tromsøbrua. Kun 17 av disse hendelsene var registrert som hopp og er med i datagrunnlaget for denne artikkelen.

FIGUR 1: Antall hopp med og uten døden til følge, på Tromsøbrua og Sandnessundbrua, før og etter sikring

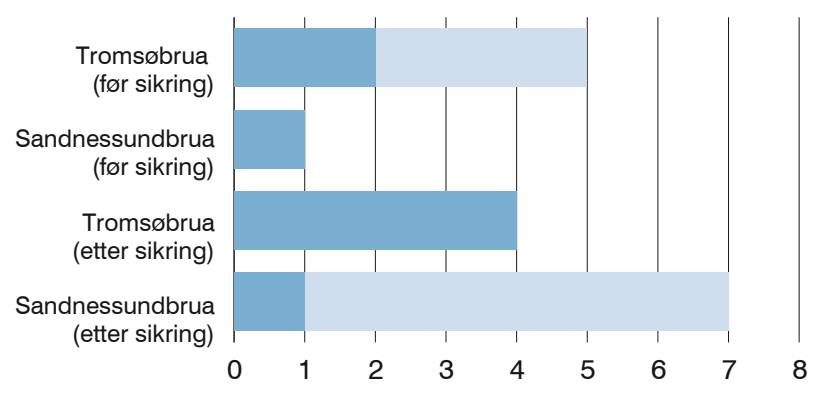

Uten døden til følge

Hopp med døden til følge

\section{Funn}

Antall utførte hopp

Etter sikring av Tromsøbrua har det blitt utført hopp både fra Sandnessundbrua og Tromsøbrua. De siste knappe to årene før sikring, fra 01.01.2004 til o9.12.2005, var det fem hopp fra Tromsøbrua. I to av fem tilfeller overlevde personen som hoppet fra brua. Etter at sikringen ble montert 09.12.2005 og fram til 31.12.2014 har det vært fire hopp fra Tromsøbrua. Til forskiell fra de som hoppet før sikring, har alle overlevd selve hoppet etter sikring av brua. Materialet vårt gir ikke informasion om noen har dødd i etterkant av redningsoperasjonen.

På Sandnessundbrua registrerte politiet ett hopp de to siste årene før Tromsøbrua ble sikret. Etter sikring har det vært utført sju hopp fra denne brua. Alle, bortsett fra ett hopp har ført til at personen døde umiddelbart (figur 1).

I de 23 månedene med registrering før sikring var det ett hopp fra Sandnessundbrua. Det utgiør ০,०4 hopp per måned. Fra Tromsøbrua var det i samme tidsrom o,22 hopp per måned. Registreringsperioden etter sikring (109 måneder) viser at det har vært o,o4 hopp per måned fra Tromsøbrua og o,o6 hopp per måned fra Sandnessundbrua.

Dersom vi ser frekvens per måned på hopp med døden til følge i samme tidsperioder på de to bruene, er frekvensen fra Sandnessundbrua lik. Fra Tromsøbrua er det 0,13 hopp med døden til følge per måned før sikring og o etter sikring.

\section{Alder}

Personene som har hoppet fra bruene i Tromsø har vært relativt unge. Registreringene på Tromsøbrua to år før sikring, viser at tre av de som hoppet var under 20 år. Til sammen fire personer var under 30 år. Etter sikring var tre av fire personer som hoppet under 30 år, en person var under 20.

Før sikring av Tromsøbrua var det en person under 30 år som hoppet fra Sandnessundbrua. Etter sikring har tre personer som har hoppet fra denne brua, vært under 30 år. Ingen har vært under 20 år (tabell 1).

TABELL 1. Antall hopp, fordelt på alder, fra Tromsøbrua og Sandnessundbrua, før og etter sikring

\begin{tabular}{|l|c|c|c|c|}
\hline Alder & \multicolumn{2}{|c|}{ Tromsøbrua } & \multicolumn{2}{|c|}{ Sandnessundorua } \\
\hline Under 20 år & $\begin{array}{c}\text { Før } \\
\text { sikring }\end{array}$ & $\begin{array}{c}\text { Etter } \\
\text { sikring }\end{array}$ & $\begin{array}{c}\text { Før } \\
\text { sikring }\end{array}$ & $\begin{array}{c}\text { Etter } \\
\text { sikring }\end{array}$ \\
\hline 20-29 år & 3 & 1 & 0 & 0 \\
\hline Over 30 år & 1 & 2 & 1 & 3 \\
\hline
\end{tabular}




\section{Kjønn}

Før sikring av Tromsøbrua var tre av hoppene utført av kvinner, to av menn. Etter at brua ble sikret har to kvinner og to menn hoppet.

Ingen menn hoppet fra Sandnessundbrua før sikring av Tromsøbrua. Etter sikring har to kvinner og fem menn hoppet fra denne brua (tabell 2).

Når vi ser kjønn og alder under ett for begge bruene, etter sikring av Tromsøbrua, har to av fire kvinner som hoppet vært under 30 år. Fire av sju menn har vært under 30 år (tabell 3).

\section{Drøfting}

\section{Hva vet vi om de som hopper}

Flere studier viser at det er flest unge menn med psykiske lidelser som velger utsprang fra høyt sted som selvmordsmetode (Beautrais \& Gibb, 2009). De som har hoppet fra Troms $ø$ - og Sandnessundbrua i perioden etter sikring, er først og fremst unge menn under 30 år. Deres psykiske tilstand har vi ingen informasion om. Registreringene to år før sikring viser at det da var flest unge kvinner som hoppet. Siden selvmord ved utsprang fra bru er en relativt sjelden metode kan andelen kvinner som tok livet sitt ved å hoppe fra bruene i registreringsperioden før sikring, skyldes tilfeldigheter. Samtidig viser annen forskning på selvmord ved hopp fra bruer i Norge (Sæheim et al. 2016) til at en relativt stor andel unge kvinner tar livet sitt ved å hoppe fra bruer. Hva som giør at flere unge kvinner ser ut til å velge å hoppe fra bru for å ta livet sitt, er det vanskelig å si noe sikkert om (ibid.)

Personene som har hoppet fra Tromsøbrua før den ble sikret var yngre enn de som har hoppet etter sikring. En av bekymringene i forkant av sikringa, var den unge alderen (under 20 år) til personene som døde av hopp fra brua. Vi finner ikke den samme aldersgruppa blant de som har hoppet fra Sandnessundbrua etter sikring av Tromsøbrua. I forhold til den yngste aldersgruppa, kan dette muligens henge sammen med at sikringen av Tromsøbrua har hatt en selvmordsforebyggende effekt.

TABELL. Antall hopp, fordelt på kjønn, fra Tromsøbrua og Sandnessundbrua, før og etter sikring

\begin{tabular}{|l|c|c|c|c|}
\hline Kjonn & \multicolumn{2}{|c|}{ Tromsobrua } & \multicolumn{2}{|c|}{ Sandnessundorua } \\
\hline Kvinne & $\begin{array}{c}\text { Før } \\
\text { sikring }\end{array}$ & $\begin{array}{c}\text { Etter } \\
\text { sikring }\end{array}$ & $\begin{array}{c}\text { Før } \\
\text { sikring }\end{array}$ & $\begin{array}{c}\text { Etter } \\
\text { sikring }\end{array}$ \\
\hline Mann & 3 & 2 & 1 & 2 \\
\hline
\end{tabular}

\section{Å vinne tid}

Personer med selvmordstanker er ofte ambivalente i forhold til sitt ønske om å dø. Intensiteten i selvmordstankene kan variere over tid. Pirkis og kollegaer (2013) viser at å hindre tilgang til metode er spesielt effektivt i tilfeller der personen er usikker på om han/hun vil dø og overfor de som handler på impuls. Whitmer og Woods (2013) viser til hvordan ulike selvmordsforebyggende tiltak som fotpatruljer, hjelpetelefoner og stenging av fortau har bidratt til å forhindre opp mot 2/3 av alle forsøk på hopp fra Golden Gate Bridge i San Fransisco. På tross av dette, viser forskerne til at det årlige selvmordstallet på denne brua har fortsatt å stige. I 2010 ble det besluttet å sikre Golden Gate med fysiske barrierer.

Et argument for å sikre Tromsøbrua med forhøyet rekkverk var at de som hadde dødd var unge mennesker man antok handlet på impuls. En fysisk hindring kan tenkes å være mer forebyggende for å handle på impuls enn andre sikringstiltak som hielpetelefoner og videoovervåkning. Disse tiltakene retter seg i større grad mot ambivalensen i selvmordsprosessen og til personer som ville tatt imot hielp der muligheten er til stede.

I følge politiet i Tromsø har sikringstiltaket trolig ført til at den suicidale personen får tid til ny overveielse og inngripen fra andre blir mer sannsynlig. Det betyr at vitner til aktiviteten har mulighet til å snakke personene fra å hoppe og kan varsle politiet. Redningsmannskap har dermed mulighet til å komme raskt til stedet, hindre at noen hopper og få personen opp av vannet dersom vedkommende har hoppet. Alle personene som har hoppet fra Tromsøbrua etter sikring har overlevd selve hoppet. Sæheim et al. (2016) fant at i 28 prosent av selvmordene utført ved bruhopp i perioden 1999-2010 var drukning medvirkende dødsårsak. På bakgrunn av dette, kan vi anta at flere av de som har dødd av hopp fra brua før sikring ikke har dødd av selve fallet, men av drukning.

TABELL 3. Antall hopp etter kjønn og alder, på begge bruene etter sikring

\begin{tabular}{|l|l|l|}
\hline \multicolumn{1}{|l|}{ Alder } & \multicolumn{2}{|c|}{ Tromso-og Sandinessund brua } \\
& Kvinne & Mann \\
\hline Under 30 år & 2 & 4 \\
\hline Over 30 år & 2 & 3 \\
\hline
\end{tabular}




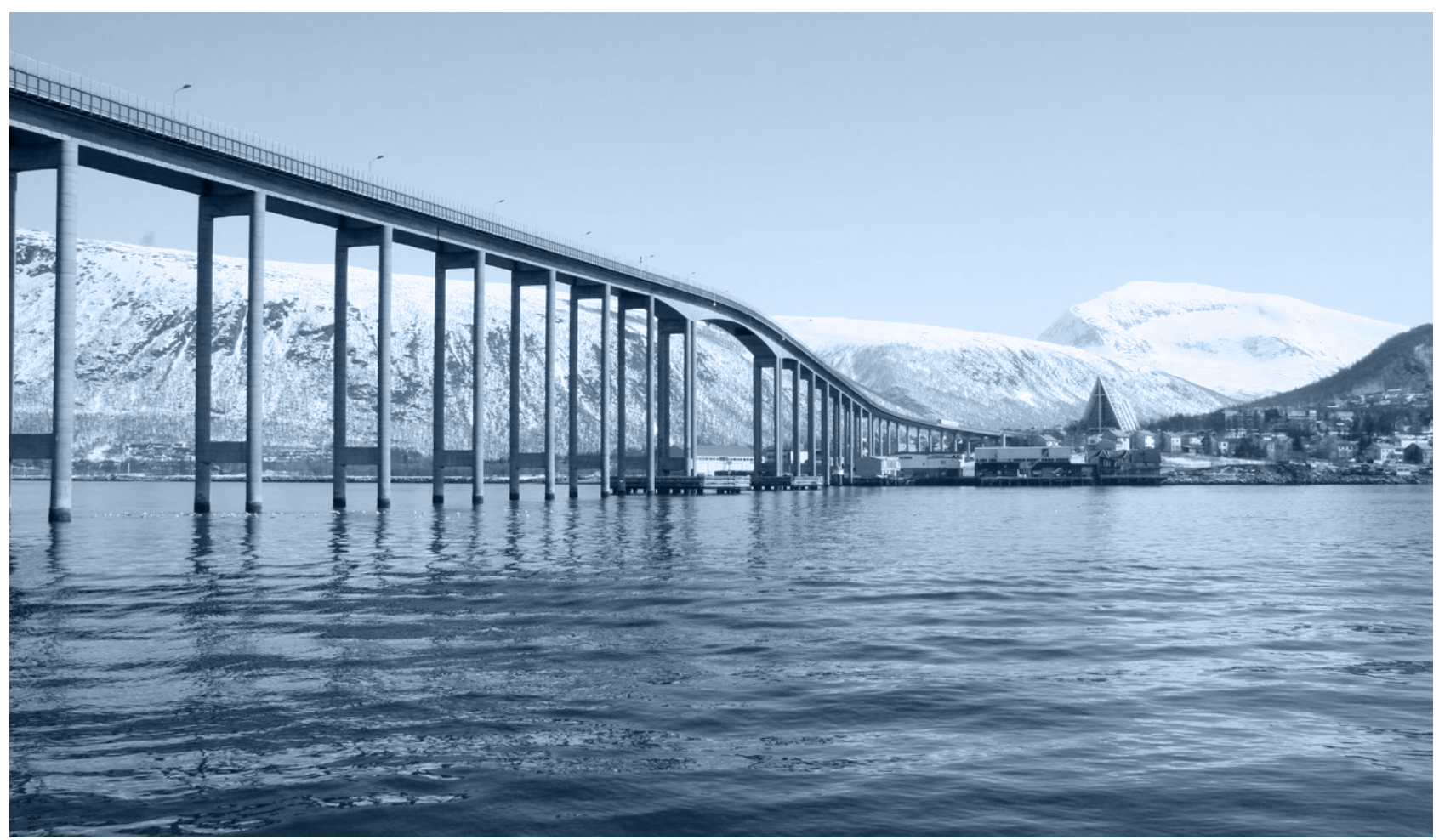

Tromsøbrua binder Tromsøya til fastlandet i Tromsdalen. Foto: Ann Karin Furskognes.

\section{Forflytting av aktivitet etter sikring av Tromsøbrua}

Et spørsmål som ofte dukker opp i diskusjoner om sikring av bruer er: «Vil de som tenker på å ta livet sitt, finne en annen metode eller gå til en annen bru?» Dette er et særlig relevant spørsmål i Tromsø hvor vi har to bruer innenfor en kort geografisk avstand. Forskningen gir ingen entydige svar på spørsmålet. Flere undersøkelser viser at sikring av en utsatt bru ikke førte til økning av utsprang fra andre nærliggende steder (Bennewith et al.2007; O`Carrol \& Silverman,1994; Pelletier 2007). Siynor og Levitt (2010) fant derimot en økning av selvmord fra andre utsprangssteder i Toronto etter sikring av et utsatt utsprangssted.

Våre data viser at det ikke har vært en økning av dødsfall ved hopp fra Sandnessundbrua etter sikring av Tromsøbrua. På Tromsøbrua har det ikke vært hopp med døden til følge etter sikring. Til tross for små tall som betyr at vi må være forsiktig med å trekke bastante konklusjoner, kan vi si at sikringen har hatt en forebyggende effekt. Både generelt og i forhold til den unge aldersgruppen som døde ved hopp fra Tromsøbrua før sikring. I forkant av sikringen av Tromsøbrua var det en bekymring for at brua var i ferd med å utvikle seg til et «hotspot» for unge, fortvilede mennesker. Golden Gate Bridge er kanskje den mest kjente «hotspoten» i verden. I en oppfølgingsstudie av overlevende etter hopp fra Golden Gate (Rosen, 1975) sa fire av seks at de ikke ville ha valgt en annen metode dersom Golden Gate Bridge ikke var tilgiengelig. Registeringsmaterialet vårt fra politiet, med informasjon om kjønn og fødselsår, viser at ingen av de som hoppet og overlevde fra Tromsøbrua etter at den ble sikret har tatt livet sitt ved å hoppe fra Sandnessundbrua per utgangen av 2014. De samme personene har altså ikke forflyttet seg til den andre nærliggende brua. Vi har ingen informasion om de har valgt andre selvmordsmetoder eller fremdeles er i live.

\section{Styrker og svakheter ved studien}

Selvmord ved utsprang fra bru er en lite brukt selvmordsmetode, derfor blir det små tall når vi bare studerer to bruer. Det betyr at vi ikke kan trekke ufravikelige konklusjoner om sikringens konsekvenser om hopp fra bruene, hva som kjennetegner de som utfører aktiviteten eller selvmordsforebygging mer generelt. Evalueringen av sikringen av Tromsøbrua gir likevel noen indikasjoner på virkningen av sikringstiltaket og dermed mer kunnskap om brusikring som selvmordsforebyggende tiltak i Tromsø.

\section{Konklusjon}

Hovedmålsettingen med å sikre Tromsøbrua, var å forhindre at personer døde som følge av hopp fra brua. Et høyere rekkverk giør det vanskeligere å hoppe. Det har blitt hoppet fra begge bruene etter sikring. I henhold til målsettingen viser vårt datamateriale at personer som hopper fra Tromsøbrua etter sikring, 
i mindre grad enn tidligere dør av selve hoppet. De blir reddet av tilfeldig forbipasserende eller redningstienesten. Dette kan tyde på at sikring av brua har bidratt til å redde liv.

Det er vanskelig å dokumentere effekten av forebyggende tiltak generelt. Selvmord ved utsprang fra bru er et relativt lavfrekvent fenomen. Sæheim et.al (2016) viser til at det gielder én prosent av selvmord i Norge 1999-2010. Det giør det vanskelig å dokumentere effekten av et slikt tiltak. Summen av forskning og erfaring knyttet til selvmordsforebygging ved sikring av utsprangssteder viser til at det har en forebyggende effekt. Vårt datamateriale støtter opp om behovet for å tenke brusikring som selvmordsforebyggende tiltak i planleggingen av nye bruer (Beautrais et al. 2009).

\section{Avsluttende kommentar}

I denne artikkelen har vi avgrenset oss til å se på hopp fra Tromsøbrua og Sandnessundbrua, og stilt oss spørsmålet: «Har sikring av Tromsøbrua hindra selvmord?» Vårt datamateriale inneholder i tillegg informasjon om aktivitet på bruene som ikke ender med hopp. Denne aktiviteten kan være farlig selv om intensjonen for den enkelte ikke er å dø. Dette trenger vi mer kunnskap om, og et spørsmål er: «Kan sikring av brua også ha en forebyggende effekt for denne gruppa?» Vårt datamateriale alene kan ikke besvare dette spørsmålet. For å giøre det er det behov for å supplere med erfaringsbasert kunnskap fra fagpersoner som møter disse personene innen psykiatrien, og ikke minst fra de personene som utfører denne type aktivitet. Personer som har ulik risikoatferd på bruene har sannsynligvis viktig kunnskap om hva som kan være gode forebyggingstiltak og god sikring av aktuelle bruer.

Levert: 20.03.18 - Revidert: 15.08.18 - Godkjent: 17.08.18

\section{REFERANSER}

Beautrais, A., Gibb, S.I., Fergusson, S.M., Horwood, L.J. \& Larkin, G.L. (2009). Removing bridge barriers stimulates suicide: an unfortunate natural experiment. Aust N Z I Psyciatry, 43: 495-97.

Beautrais, A. \& Gidd, S. (2009). Protecting bridges and high buildings in suicide prevention. I Wasserman, D. \& Wasserman, C. (ed) (2009). Oxford textbook of Suicidology and Suicide Prevention. Oxford University Press.

Berntsen, G. \& Larssen, M. (2011). Evaluering av sikringstiltak på Tromsøbrua etter fem år. Rapport, RVTS Nord.

Berntsen, G \& Larssen, M. (2016). Har sikring av Tromsøbrua hindra selvmord? Sluttrapport fra RVTS Nord basert på datamateriale to år for sikringa ble påmontert i $2005 \mathrm{og}$ ni år etter.

Elnour, A. A., \& Harrison, I. (2008). Lethality of suicide methods. Injury Prevention, 14, 39-45.

Furskognes, A.K. (2008): Evaluering av brusikringstiltak påmontert Tromsøbrua 9. desember 2005

Gunnell, D. Nowers, M. \& Bennewith, O. (2005): Kan selvmord ved hopping forhindres? Suicidologi, 10(2), 15-17.
Gunnell, D. \& Nowers, M. (1997). Suicide by jumping. Acta Psychiatric Scan, 96: 1-6.

Larsen, K. \& Karlsen, K. (2016). Selvmord ved utsprang fra høyt sted. Tidsskrift for norsk psykologforening. S.118-126.

Mann, I.I., Apter, A., Bertolote, I. et al. (2005). Suicide prevention strategies: A systematic review. IAMA 2005; 294: 2064-74.

Mehlum, L. (2005). Forebygging giennom begrensningen av tilgang til selvmordsmidler. Suicidologi, 10(2).

Nasjonalt senter for selvmordsforskning og -forebygging (2016): Selvmords metode etter kiønn. Utvalgte år. Prosentvis fordeling https://www.med.uio. no/klinmed/forskning/sentre/nssf/kunnskapsressurser/statistikk-selvmord/ statistikk-2015/kjonn-og-dodsmate prosentvis-fordeling-utvalgte-ar.pdf (lastet ned $04.07 .17 \mathrm{kl} .15 .26$ ).

Pirkis, I., Spittal, M.I., Cox, G., Robinson, I., Cheung, Y.T.D \& Studdert, D. (2013). The effectiveness of structural interventions at suicide hotspots: a meta-analysis. International Journal of Epidemiology, 42, 541-548.

Reisch, T \& Michel, K. (2005). Securing a suicide hotspot: effects of a safety net at the Bern Munster Terrace. Suicide and life threatening Behaviour. $35(4): 460-7$

Rosen, D. H. (1975). Suicide survivors - A follow-up study of persons who survived jumping from the Golden Gate and San Francisco-Oakland Bay Bridges. Western Tournal of Medicine, 122, 289-294.

Sarchiapone, M., Mandelli, L., Iosue, M., Andrisano, C. \& Roy, A. (2011). Controlling access to suicide means.International Journal of Environmental Research. Public Health 8: 4550-62.

Sinyor, M, \& Levitt, A. I. (2010). Effect of a barrier at Bloor street viaduct on suicide rates in Toronto: Natural experiment. BMI, 341.

Sæheim, A. \& Hestetun, I. (2013). Hva vet vi om sikring av bru som selvmordsforebyggende tiltak? Suicidologi 18 (2).

Sæheim, A., Hestetun, I., Mork, E., Nrugham, L. \& Mehlum, L. (2017). A 12 year National Study of Suicide by Jumping From Bridges in Norway. Archives of Suicide Research. http://dx.doi.org/10.1080/13811118.2016.1199988

Whitmer, D.A \& Woods, D.L. (2013). Analysis of the cost effectiveness of a suicide barrier on the Golden Gate Bridge Crisis, 34, 98-106.

World Health Organization (2008). Preventing suicide: a resource for media professionals.

http://www.helsebiblioteket.no/pasientinformasion/psykisk-helse/ posttraumatisk-stresslidelse

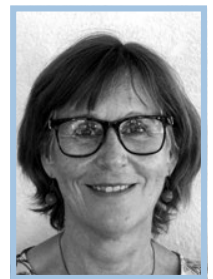

GRO BERNTSEN er barnevernspedagog og sosialantropolog. Hun jobber ved RVTS Nord med selvmordsforebygging.

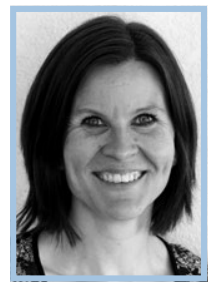

MARIANNE LARSSEN er sosiolog. Hun jobber ved RVTS Nord med selvmordsforebygging. 